Sharif, A.M. (1999). "Harnessing agile concepts for the development of Intelligent Systems". New Generation Computing, 17 (4) : 369-380.

\title{
Harnessing Agile concepts for the Development of Intelligent Systems
}

\author{
Amir M. SHARIF \\ Department of Information Systems and Computing \\ Brunel University \\ Uxbridge, Middlesex, UB8 3PH, GREAT BRITAIN \\ Amir.Sharif@brunel.ac.uk
}

Submission date : 31/1/99

Resubmission date after revisions : 8/4/99 
Sharif, A.M. (1999). "Harnessing agile concepts for the development of Intelligent Systems". New Generation Computing, 17 (4) : 369-380.

\title{
Harnessing Agile concepts for the Development of Intelligent Systems
}

\begin{abstract}
Traditional and current approaches to intelligent systems design, have led to the creation of sophisticated and computationally-intensive packages and environments, for a wide range of applications. This paper proposes methods with which to extend the functionality of such systems, borrowing knowledge management concepts from the field of Agile Manufacturing. As such, this paper proposes that the future of intelligent systems design should be based not only upon the continuing development of artificial intelligence techniques, but also effective methods for harnessing human skills and core competencies to achieve these aims.
\end{abstract}

Keywords : Artificial Intelligence, Agile Manufacturing, Neuro-Evolutionary Systems 
Sharif, A.M. (1999). "Harnessing agile concepts for the development of Intelligent Systems". New Generation Computing, 17 (4) : 369-380.

\section{Introduction}

Since the advent of the computer, scientists have been attempting to rationalise and simulate human creative and higher brain function processes, such as reasoning, problem-solving, and lately, music and $\operatorname{art}^{20)}$. Early forays into designing computational systems which would exhibit some form of Artificial Intelligence (AI), were mainly concerned with generating rule predicates through symbolic representation. These were as a means of helping users carry out mundane, data and evaluation-intensive processes, often with multiple and varying constraints ${ }^{11)}$. The transfer of knowledge from humanexpert to computer-expert, has in essence become a de facto approach to the design of many intelligent systems in business and engineering ${ }^{5,22,27)}$. Computational paradigms have attempted to model processes based upon learning and classification of patterns ${ }^{2)}$ and optimisation and control ${ }^{12,16)}$ through neural and evolutionary processes respectively. All these avenues of research have yielded what we now know today as Knowledge-Based Expert Systems, Neural Networks and Evolutionary / Genetically-inspired schemes.

In the former case, this is commonly achieved through eliciting knowledge from human experts, via interviewing and / or decision modelling techniques. The latter case, on the other hand, does not typically require such a deep knowledge representation scheme as expert systems do. Instead, the definition of an objective function is required which relates key parameters of the system which are to be optimised in some sense (a maximisation or minimisation). A key feature of all of these types of intelligent system, is that these techniques traditionally require a mapping between the problem space (i.e. real-world variables) and the solution space (i.e. computed values in the intelligent system). Such mappings are then encoded into the intelligent system through traditional software engineering and programming concepts, which historically, has yielded a significantly large number of excellent problemsolving packages. However, there appears to be little in the way of ensuring that the development of such AI approaches is both consistent and adaptable to the changing needs of human users and the respective domain of application. 
Sharif, A.M. (1999). "Harnessing agile concepts for the development of Intelligent Systems". New Generation Computing, 17 (4) : 369-380.

This paper seeks to highlight issues relating to the development of intelligent systems in this regard, in terms of the flexibility of users needs when when using such systems. Through this realisation, concepts of agility are applied to build upon upon traditional approaches to artificial intelligence-based systems. This is in terms of the contribution that both the intelligent system and human users can make to each other, in terms the transfer, representation and effective management of knowledge processes within an information system. In the remaining sections of this paper, a brief critique of current intelligent system design and methodology is given (Section 2), after which the basis for extending these notions towards flexible and adaptable systems are described via concepts of Agility and Agile Manufacturing (Section 3). Finally, a conceptual model which congolomorates these ideas is given, as a basis for outlining methods by which intelligent systems can, and may be, developed in the future (Section 4).

\section{Intelligent Systems design methodologies}

The attributes that an intelligent system should display are that the way in which knowledge is structured and represented within it, should be adaptable relative to its environment. Secondly, it should have the ability to display and augment intelligent behaviour, inwardly in its processes and outwardly, in relation to interacting with a human user. However, this cannot always be achieved and some developmental bottlenecks in intelligent systems design are outlined in Table 1 highlighting this. Much research has focussed on efforts to produce systems, which echo methods by which human experts carry out knowledge and process manipulation tasks. As shown in Figure 1, in the representation phase, parameters to be modelled are defined, along with any constraint information. The computation and discrimination phases, in reality, overlap each other in that they both entail the problem-solving and evaluation aspects of the system. The power of an intelligent system does not so much lie with the brute force of computation, but increasingly with the power to discriminate data and information. 
Sharif, A.M. (1999). "Harnessing agile concepts for the development of Intelligent Systems". New Generation Computing, 17 (4) : 369-380.

Table 1. A taxonomy of software engineering and human issues in intelligent systems design

\begin{tabular}{|c|c|}
\hline $\begin{array}{c}\text { Software Engineering } \\
\text { Aspects }\end{array}$ & $\begin{array}{l}\text { Human Process } \\
\text { Aspects }\end{array}$ \\
\hline $\begin{array}{l}\text { - AI development lifecycle uses } \\
\text { waterfall approach : and does not } \\
\text { utilise current 'best practice' software } \\
\text { methods }\end{array}$ & $\begin{array}{l}\text { Intelligent systems design, indirectly } \\
\text { analogous to human processes of } \\
\text { concept formation and problem } \\
\text { solution. }\end{array}$ \\
\hline $\begin{array}{l}\text { - Neo-classicist AI amenable to Rapid } \\
\text { Application Prototyping (RAD) and } \\
\text { object-oriented methods }{ }^{35)} \text {. }\end{array}$ & $\begin{array}{l}\text { - Discrimination / evaluation phase } \\
\text { highly dependant upon expert / } \\
\text { domain knowledge. }\end{array}$ \\
\hline $\begin{array}{l}\text { - Involves specialist domain experts } \\
\text { (individuals) rather than teams }{ }^{34)}: \text { is } \\
\text { the system intelligent or is the human } \\
\text { developer intelligent } \text { ? }^{20)}\end{array}$ & $\begin{array}{l}\text { - Mapping expert / real-world } \\
\text { knowledge to objective and weighting } \\
\text { functions, is an art and difficult to } \\
\text { achieve. }\end{array}$ \\
\hline $\begin{array}{l}\text { - Specifications usually based upon } \\
\text { expectations of observable intelligent } \\
\text { behaviour (i.e. level of describable } \\
\text { results upon an implementation of the } \\
\text { system). }\end{array}$ & $\begin{array}{l}\text { Rate of learning for the human user is } \\
\text { non-linear }{ }^{30)}: \text { user has to become the } \\
\text { domain expert as well as domain } \\
\text { analyst (multiple responsibilities). }\end{array}$ \\
\hline $\begin{array}{l}\text { - Uniqueness of representations within } \\
\text { knowledge-based and neuro- } \\
\text { evolutionary methods highlights } \\
\text { relativistic nature of AI models and } \\
\text { implementations. }\end{array}$ & $\begin{array}{l}\text { - Heavily empirical nature of AI has } \\
\text { attempted to use evaluative methods } \\
\text { based upon heuristics }{ }^{1,32)} \text {, biological } \\
\text { behaviours }^{7)} \text {, philosophy of science }{ }^{9,24)} \\
\text { or traditional symbolic logic }^{3,29)} \text {. }\end{array}$ \\
\hline $\begin{array}{l}\text { - Outward functionality determines } \\
\text { intelligent systems role (function- } \\
\text { replacing or function-replicating). }\end{array}$ & $\begin{array}{l}\text { - Few 'best of breed' solutions exist for } \\
\text { problems typified as solvable by AI } \\
\text { methods and techniques : lack of a } \\
\text { systems-wide methodology is apparent. }\end{array}$ \\
\hline
\end{tabular}

The antithesis of any intelligent system is to replicate human / natural actions (needs-focussed), whilst at the same time trying to find non-trivial solutions to processes or data (computation-focussed). This can result in a fatal deadlock, through the indirect bias of the human expert who is modelling and utilising such a system. This paper proposes a framework for the development of intelligent systems, based upon agile manufacturing concepts which can help alleviate some of these issues. 
Sharif, A.M. (1999). "Harnessing agile concepts for the development of Intelligent Systems". New Generation Computing, 17 (4) : 369-380.

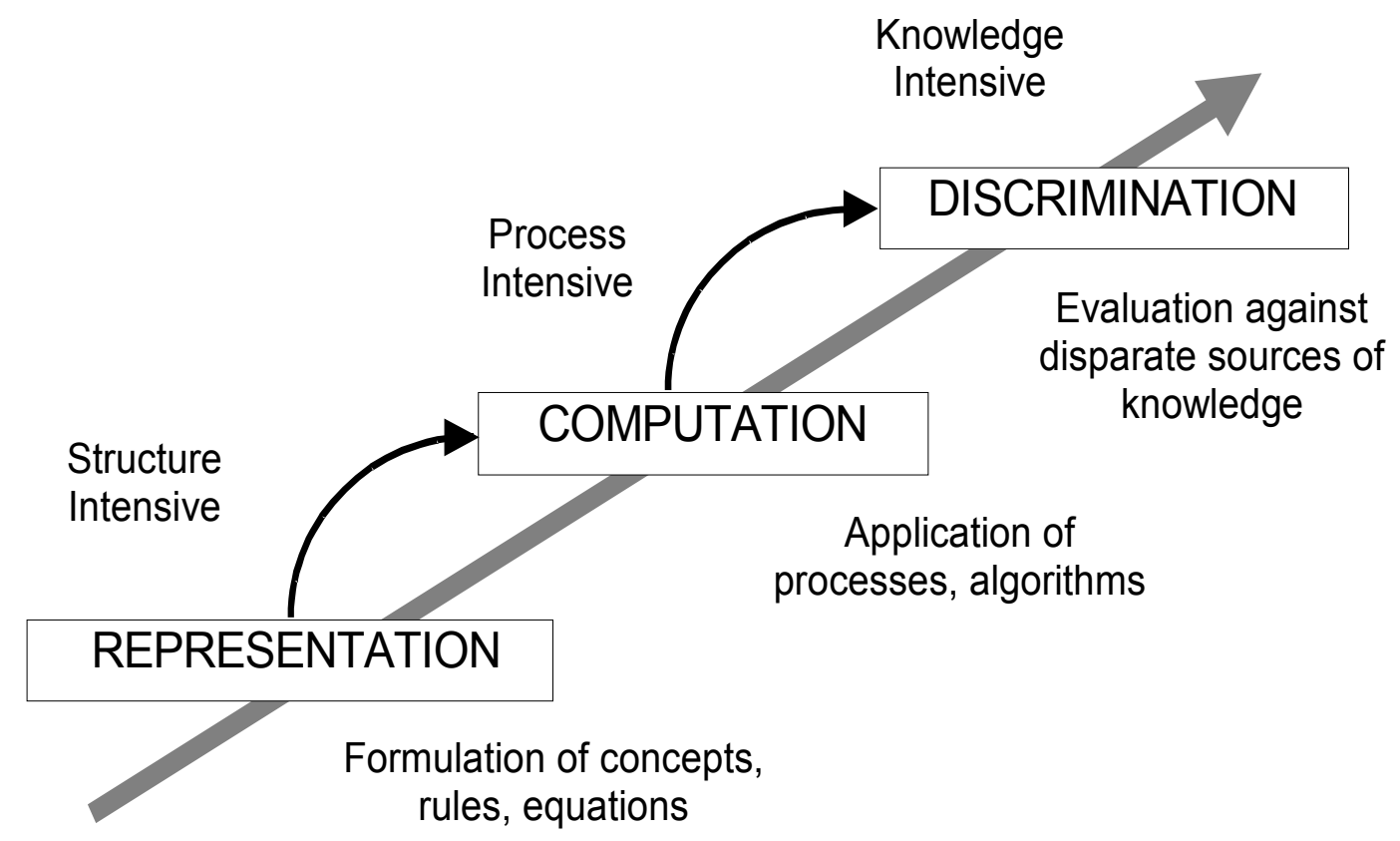

Fig. 1 Three phases of Intelligent System development

\section{Developing Agile Intelligent Systems}

Intelligent systems can provide many interesting means of problemsolving, decision support and process simulation, as can be seen from a review of the literature ${ }^{27)}$. It has also become increasingly apparent that the greatest advantages in applying artificial intelligence, comes from taking advantage of the best aspects of each type of technology. This can either be via central control mechanism (an intercommunicating intelligent system) or via a common processing architecture (a polymorphic intelligent system) $)^{14,17)}$. In order to realise benefits of such approaches the following section introduces the concept of agility of a system in terms of the Agile Manufacturing scenario.

\subsection{What is Agile Manufacturing ?}

The growth of a truly dynamic global marketplace has meant that manufacturing, as well as service, organisations must somehow attract a greater number of customers (to maintain and secure business), and minimise subject to a maximisation of available resources ${ }^{15)}$. As has been suggested in the literature and industrial community, this difficult optimisation can only be solved through 
Sharif, A.M. (1999). "Harnessing agile concepts for the development of Intelligent Systems". New Generation Computing, 17 (4) : 369-380.

the use of innovative processes, products, and practices which will allow organisations to maintain a strategic advantage over their competitors ${ }^{23)}$. Agility (and specifically, Agile Manufacturing) is a business concept, which attempts to resolve this issue through adapting organisational processes and practices via a combination of managing the organisation, its people and its technology within a rapidly changing business environment ${ }^{18)}$. Four key dimensions, which describe agility, which have been described by Goldman et al. ${ }^{13)}$ and are reproduced in Table 2 . In order to satisfy these goals, numerous strategies are available, both strategic as well as operational but these remain to be highly context sensitive varying from organisation to organisation and from sector to sector. The key to application of the agile concept, is to understand customer and market needs, and also strengths and weaknesses of competitors in order to adapt business processes effectively. Most importantly, a successful agile firm is one which routinely manages change for the benefit of the organisation's growth and operational stability, largely through an integration of organisational functions and knowledge structures.

\subsection{Developing Agile Intelligent Systems}

By comparing the traditional view of what constitutes an intelligent system against the philosophy of an agile system in the previous section, we can see that AI implementations are, in part, against the spirit of the agile manufacturing concept. They have a lack of flexibility; slow responsiveness; are not very user-friendly; and are, traditionally, complex (i.e. powerful only in the hands of the expert). Agile concepts continually stress effective knowledge management through the distinction of two approaches to utilising knowledge.

The 'interventionist' approach, which has been tacitly held in the AI, and more specifically, in the expert systems community is it is argued that a human expert will always have to be at hand in order to reconstruct and direct augmented and elicited knowledge for problem-solving and decision support situations. A sufficient granularity of knowledge cannot be embedded into a knowledge base because this would entail describing a multitudinous number of potential cases, which cannot easily be stored, and accessed ${ }^{11)}$. 
Sharif, A.M. (1999). "Harnessing agile concepts for the development of Intelligent Systems". New Generation Computing, 17 (4) : 369-380.

Table 2. An overview of Agile Concepts

\begin{tabular}{|c|c|}
\hline Dimensions & Characteristics \\
\hline Enriching the customer : & $\square$ Flexibility \\
\hline $\begin{array}{l}\text { Understanding the needs of the } \\
\text { customer and satisfying them. }\end{array}$ & $\begin{array}{l}\text { (adaptibility) } \\
\square \quad \text { Leanness } \\
\text { (i.e. 'doing more with less') }\end{array}$ \\
\hline $\begin{array}{l}\text { Co-operating to enhance } \\
\text { competitiveness : }\end{array}$ & $\square \quad$ Concurrency \\
\hline $\begin{array}{l}\text { Creating inter- and intra- } \\
\text { organisational alliances for mutual } \\
\text { benefit. }\end{array}$ & $\begin{array}{l}\text { Responsiveness } \\
\text { (short cycle times) }\end{array}$ \\
\hline $\begin{array}{l}\text { Organising to master change } \\
\text { and uncertainty : }\end{array}$ & $\begin{array}{l}\text { Value adding quality } \\
\text { practices (a TQM philosophy) }\end{array}$ \\
\hline $\begin{array}{l}\text { Utilising organisational structures in } \\
\text { order to facilitate the management of } \\
\text { change. }\end{array}$ & $\begin{array}{l}\square \quad \text { 'Virtual' resource pool } \\
\text { (customers, competitors, markets) }\end{array}$ \\
\hline & $\begin{array}{l}\text { Integration (technology, process, } \\
\text { culture and social values) }\end{array}$ \\
\hline $\begin{array}{l}\text { Using knowledge and people } \\
\text { effectively : }\end{array}$ & $\square \quad$ Accessibility and Use \\
\hline $\begin{array}{l}\text { Recognising that employees are company } \\
\text { assets which can be used to leverage the } \\
\text { impact of technology and information. }\end{array}$ & $\begin{array}{l}\text { ('intelligent' usage of knowledge } \\
\text { organisational, teams, individuals) }\end{array}$ \\
\hline
\end{tabular}

In contrast, the 'integrationist' philosophy supported on the basis of the Agile Manufacturing concept, is that human knowledge should be accessible as and when. In holistic terms, such domain-focussed knowledge should always play an imperative part within the life cycle of a project. Intelligent assistance should be a transparent attribute of any such system, and should rather be part of a practice and philosophy of (human-based) processes (such as within a knowledge-based learning organisation). Because AI has been, and will continue to be, a technological panacea the interventionist approach is becoming increasingly brittle due to a reliance upon knowledge structures, rather than knowledge dialogue. Representing and applying the right computational technique at the right time in the problem-solving lifecycle is key to this concept and an approach to this is given in the following section. 
Sharif, A.M. (1999). "Harnessing agile concepts for the development of Intelligent Systems". New Generation Computing, 17 (4) : 369-380.

\section{A conceptual AgIS model}

Drawing upon the discussion presented in the previous sections of this paper, a conceptual model of an Agile Intelligent System (AgIS) is now presented. Extending Kidd's description of the freedom of design choices, an analogy can be made towards how an agile intelligent system should address the various factors that have been discussed thus far in this paper. This is shown in Figure 2. Focussing on the analogy between a typical design process within a manufacturing life cycle, this figure proposes that a lifecycle which highlights the scope of application of an AgIS.

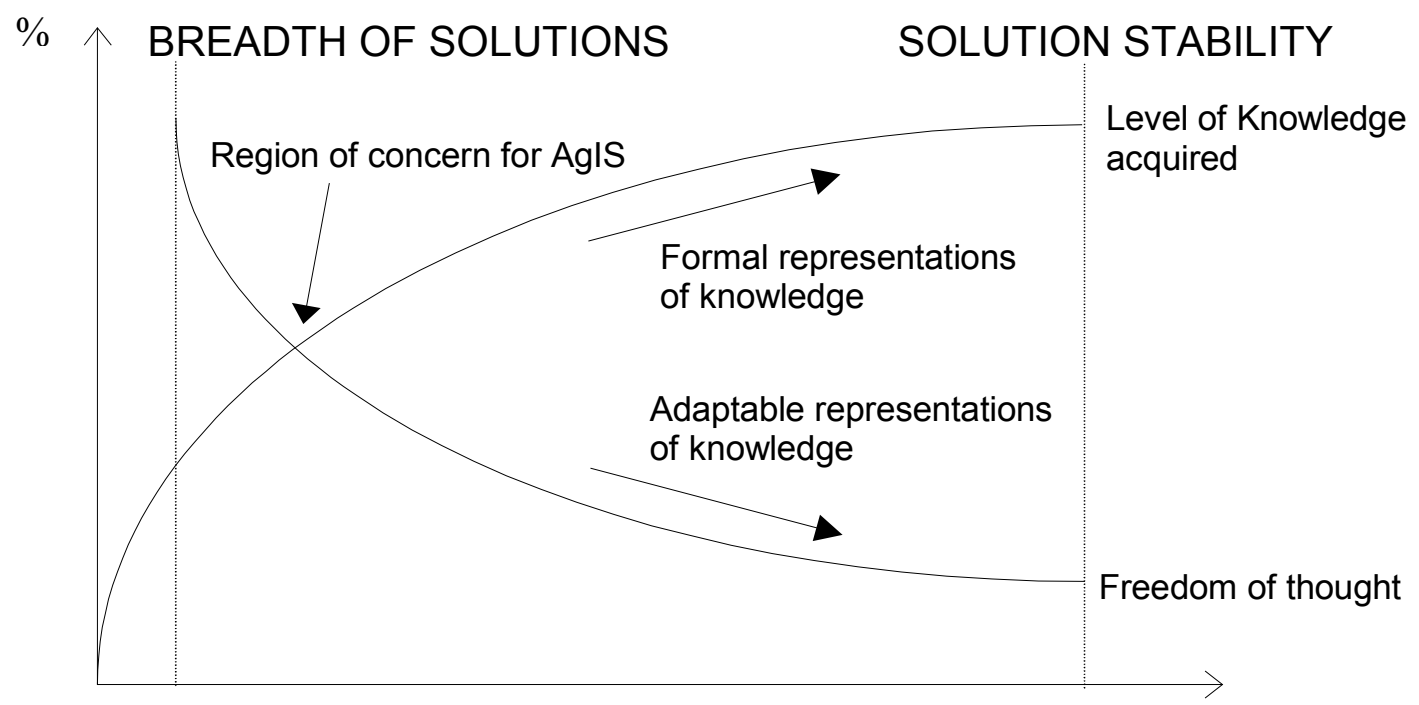

Time

Fig. 2 Scope of application for Agile Intelligent Systems

Principally, an AgIS should be transparent to the needs of being constrained to the level of knowledge encoded within the system, and also the means, to acquiring a solution to a design problem. It should be able to provide exploratory solutions when required (indicated by the legend, 'Breadth of solutions'), and maintain a diversity of paths to knowledge, within the mean time of the design lifecycle (indicated on the horizontal $\mathrm{x}$-axis as 'Time'). Both of these facets should enable innovative processes to be created and, as such, should empower the user to remain in control of the intelligent system. 
Sharif, A.M. (1999). "Harnessing agile concepts for the development of Intelligent Systems". New Generation Computing, 17 (4) : 369-380.

\subsection{Enablers for an Agile Intelligent System}

\subsubsection{User-centred development of AI systems}

This entails a development of methods and practices for enabling users to get the most out of an intelligent system, which involves providing access to problem, individual, team, organisational-level or associated knowledge which may be indirectly helpful. When users are faced with a new modelling environment which may require require a high degree of motivation and skill to use, collaborative assistance from the intelligent system in the early stages of usage, would be highly beneficial.

\subsubsection{Functionality and Augmentation}

The functional power of intelligent computational techniques should ultimately be transparent to the user. The delegation of control to a number of dedicated system agents that automatically detect when and where a particular intelligent 'engine' should be used, (as discussed by Rzevski ${ }^{25)}$ ). Secondly, the user should notice that their interaction with such a system may produce an implicit, positive increase in their own modelling and reasoning processes. This increase, or augmentation, should not be at the expense of the system forcing the its own knowledge on the user, but rather on the (meta-) intelligence of the system recognising when knowledge and / or assistance should be applied.

\subsection{3 'Closing the Loop' - An Agile Intelligent System (AgIS)}

A truly agile intelligent system, should not only encompass features of usability, responsiveness, leanness, flexibility and intercommunication but also distinguish itself by means of being adaptable to the needs of the user directly. This involves not only assessing the rate of information being processed by the intelligent 'engine' under use at the time (e.g. neural net, knowledge base of evolutionary system) but also a metric of the rate of 'productive' (i.e. response and computation driven) work a user can carry out when using the system. This is a qualitative rather than quantitative figure, which would be, at the very least, difficult to formulate effectively. 
Sharif, A.M. (1999). "Harnessing agile concepts for the development of Intelligent Systems". New Generation Computing, 17 (4) : 369-380.

\subsection{Definition of an AgIS}

Comparing and contrasting this with the constituent characteristics of an agile system given in Section 2, this approaches the satisfaction of the fundamental goals of agility. Hence, those facets shown in Table 2 can now be put in the context of an agile intelligent system as shown in Figure 4. The development and implementation of any intelligent system should be considered as part of a wider, holistic framework, which includes human as well as technological considerations. Indeed, this is an important point when considering the usage of non-intelligent but equally powerful software within manufacturing enterprises. The AgIS concept being imparted here, focusses primarily on the nucleus of agile manufacturing theory. That is, the management of change through the integration of organisational functions, processes and knowledge.

The latter can loosely be translated to modelling constraints and computational processes, which are carried out by the system under the request of the user. Put in the context of developing future intelligent systems, this simplifies to the definition of the following agile intelligent system architecture, which facilitates integration between the user ; knowledge sources; information and knowledge representation formats; visualisation schemas (textual and / or graphical output to the user) and access to and utilisation of computational AI 'engines' and related methods of evaluation and deductive reasoning.

The AgIS system operates on a basis of agent interaction and mediation, facilitated by both the user and the components of the system. The model extends concepts of intercommunication and dialogue, which are inherent in current neuro-evolutionary systems, through a consideration of the important role that multiple agents can play ${ }^{4,85}$. Module agents primarily define a 'span of control' or operating constraints for each module. Mediators are secondary agents, which communicate directly with the user and each module agent in order to facilitate information flow. This can include low and high level information for example, the number of computational engines in use, through to rates of learning and adaption of the system to a problem posed by the user. 
Sharif, A.M. (1999). "Harnessing agile concepts for the development of Intelligent Systems". New Generation Computing, 17 (4) : 369-380.

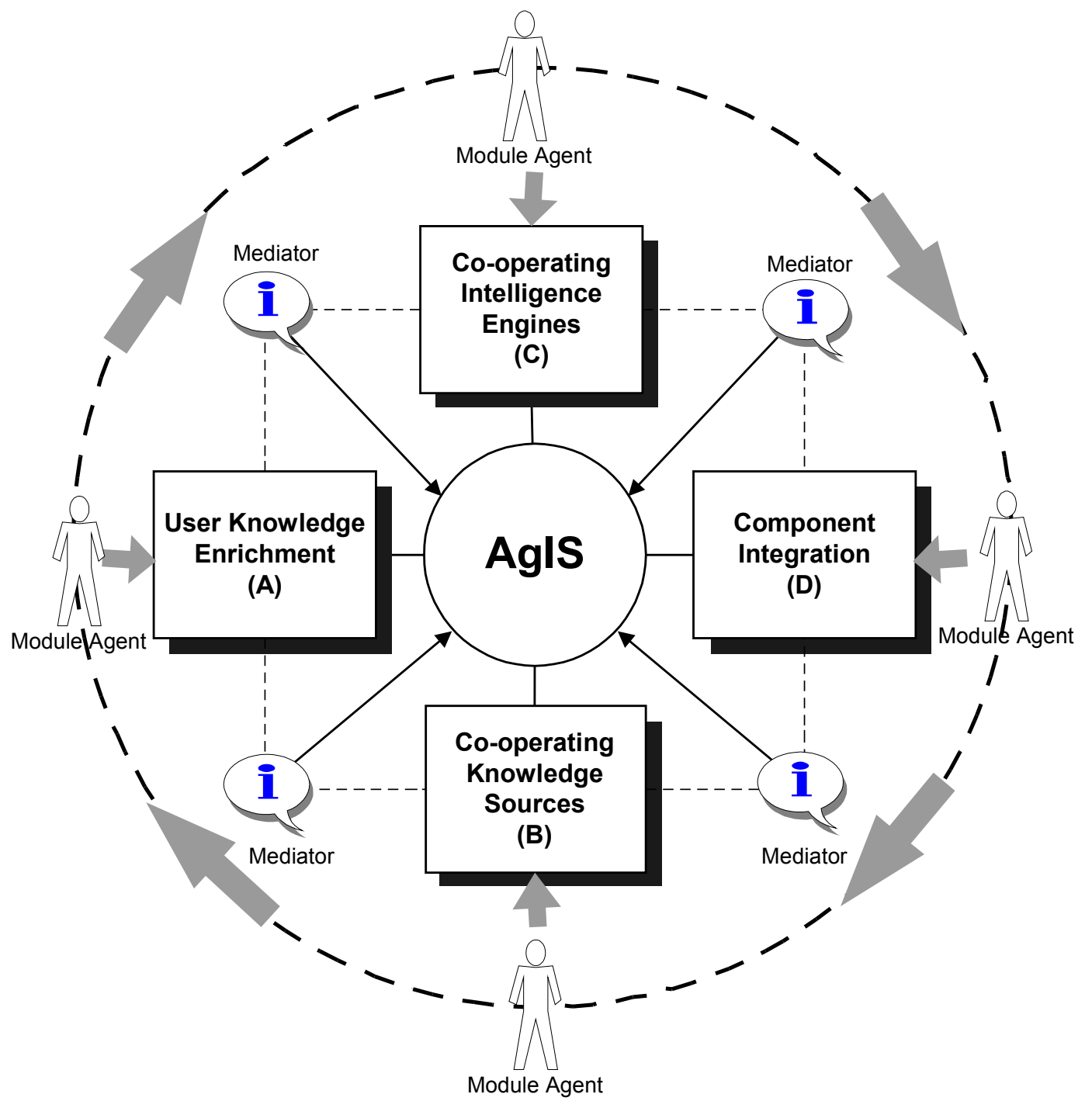

Figure 4. Conceptual model of an AgIS

The philosophy behind the operational use of an AgIS relies upon a 'push me'/'pull you' concept which is now explained. The user can interact with any of the agents who relate to either imparting further knowledge through a user interface (A); accessing and utilising a computational engine such as a neural network (C); managing the information flows between the system components (D); and activating relevant knowledge bases which are useful to the user (B). These qualities relate directly to the four dimensions of agility shown in Table 2. This is facilitated through the structure, process and knowledge supplemented by the AgIS within a problem-solving and manufacturing design environment. This also involves accessibility to indirect knowledge sources (design repetoires, organisational documents, etc.); 
Sharif, A.M. (1999). "Harnessing agile concepts for the development of Intelligent Systems". New Generation Computing, 17 (4) : 369-380.

utilisation of a control module to schedule computing tasks (e.g. inferencing, rate of learning of a neural net); formalisation and automation of repetitive problem-solving tasks (e.g. pattern classification from large datasets).

As such, there can be a 'push' of knowledge from user interaction with each agent and its associated mediator (i.e. the small arrows to the centre). The 'pull' of this knowledge between the interacting agents for each module (i.e. the dark grey arrows on the outer circle) constitutes intelligent behaviour as a result of adapting varying inputs from the user's actions. This ideal satisfies the notion of an AgIS being a tool by which knowledge is augmented, and also which can facilitate innovative processes and ideas.

\subsection{Application Context}

The context of such a system, could be as an integrated problem-solving and analysis environment for engineering analyses within a manufacturing organisation (such as proposed by Drashansky et al. ${ }^{8)}$ and Gallopoulos et al. ${ }^{9)}$ ). Comparing work processes carried out in $\mathrm{CAD} / \mathrm{FEA}$ experts in engineering organisations $^{19,21,26,33)}$ against AI systems development, it has been shown that the same traits as found in AI systems development, are largely replicated in engineering software usage. For example, on-going research into the generation of finite element (FE) meshes, a genetic algorithm approach has been used to optimise interconnecting polygonals which may be used for numerical analysis schemes $^{26,27,28)}$ (such as finite element analysis, FEA). This evolutionary AI method treated the meshing problem in terms of a solution to a multiobjective function relative to mesh distribution density, polygonal geometry and localised error estimates. However, an analysis of the modelling and definition of the problem to be solved by the genetic algorithm, still highlighted the fact that a large amount of heurism needed to be employed. This was apparent when put in the context of adjusting the objective function, selecting a relevant parameter encoding scheme and assessing intelligent behaviour of the algorithm. This was in terms of classifying the speed and performance of the system in either finding superconvergent, trivial solutions or deceptive, non trivial solutions (i.e. GA easy as opposed to GA hard ${ }^{12}$ ). 
Sharif, A.M. (1999). "Harnessing agile concepts for the development of Intelligent Systems". New Generation Computing, 17 (4) : 369-380.

By applying some of the rudimentary concepts of agility, this makes such an intelligent system appear to be highly flexible (i.e. adaptable to changing solution parameters and user needs), but not necessary lean ('doing more with less') or value-adding. This means that the user may not necessarily be able to be provided with a (sustainable) increase in knowledge and understanding about the mesh being optimised and re-generated. Metrics to describe the time involved in developing solutions to user problems with respect to the effort required to implement such systems in terms of human effort and resource costs, need to be investigated. These values can be approximated with a modest degree of accuracy, simply by reviewing AI research literature so far. Also, quantities to describe the complexity of interaction for a user with such systems would be beneficial. This would be in terms of defining metrics or codes of practice for the effective deployment of intelligent architectures and how they might best be used.

\section{Conclusions}

The paper highlighted and recapitulated some important aspects relating to intelligent systems design and development methodologies. It was argued that past and presently implemented systems such as these do not embody robust and consistent software engineering methods. Due to the empirical and exploratory nature of AI research, it may not be entirely feasible to apply such structured project management techniques to program development. Since many systems which aim to exhibit intelligence are usually written by domain and computer experts, a large amount of time is saved through the rapid prototyping of fundamental data and control structures which help achieve this aim.

This paper subsequently drew pertinent open issues together, relating to the future development and design of intelligent systems. In approaching these issues, the concept of agility borrowed from the field of Agile Manufacturing have been used to illustrate benefits which can be obtained through knowledge empowerment, flexible system structures and component integration. This provided a basis for the generation of an Agile Intelligent System (AgIS) conceptual model, which was based upon these facets. However, through 
Sharif, A.M. (1999). "Harnessing agile concepts for the development of Intelligent Systems". New Generation Computing, 17 (4) : 369-380.

parallels with engineering software, it was shown that most intelligent systems design occurs in a relativistic, empirical and unstructured manner. In terms of harnessing the power of appropriate knowledge sources (domain and other indirectly related sources), this does not make such implemented systems entirely flexible and is against the concept of agility, flexibility and leanness argued for in the paper.

Further directions and avenues of research were discussed which include the investigation of developing process and other related software metrics specifically for intelligent systems design. These would be in the form of not only technical but also user-centred quantities such as productivity, usability and knowledge augmentation metrics.

\section{References}

1) Baldwin, D., and Yadav, S.B., "Process of research investigations in artificial intelligence - a unified view", IEEE Transactions on Systems, Man and Cybernetics, 25, 5, pp.852-861, 1995.

2) Beale, R. and Jackson, T., Neural Computing - An introduction, Institute of Physics, Bristol, England, 1992.

3) Brooks, R.A., Breazeal, C., Irie, R., Kemp, C.C., Marjanovic, M., Scassellati, B., and Williamson, M.M., "Alternative essences of intelligence", Proceedings of the 1998 15th National Conference on Artificial Intelligence, AAAI, Madison, WI, USA, Jul 26-30, pp.961-968, 1998.

4) Bull, L., and Holland, O., "Evolutionary Computing in Multi-agent environments : EuSociality", Proceedings of the $2^{\text {nd }}$ International Conference on Genetic Programming (GP-97), Stanford University, July 13-16 ${ }^{\text {th }} 1997$, pp.347-352, 1997.

5) Coats, P.K., "A critical look at Expert Systems for Business Information Applications", Journal of Information Technology, 6, pp.208-216, 1991.

6) Cohen, P.R., Empirical Methods for Artificial Intelligence. Cambridge, MA, MIT Press, 1995.

7) Cohen, P.R., and Howe, A.E., "Toward AI research methodology: Three case studies in evaluation". IEEE Transactions on Systems, Man and Cybernetics, 19, 3, pp.634-646, 1989

8) Drashansky, T., Houstis, E., Ramakrishnan, N., and Rice, J.R., "Networked Agents for Scientific Computing", Communications of the ACM, 42, 3, pp.48-54, 1999.

9) Dreyfuss, H., What computers still cannot do, Reading, MA, MIT Press, 1972.

10) Gallopoulos, E., Houstis, E., and Rice, J.R., "Computer as Thinker / Doer : Problem-Solving Environments for Computational Science", IEEE Computational Science and Engineering, Summer 1994, pp.11-23, 1994. 
Sharif, A.M. (1999). "Harnessing agile concepts for the development of Intelligent Systems". New Generation Computing, 17 (4) : 369-380.

11) Genesereth, M.R., and Nilsson, N.J., Logical foundations of Artificial Intelligence, Morgan Kaufmann, 1987.

12) Goldberg, D.E., Genetic Algorithms in Search, Optimisation and Machine Learning. Reading, M, Addison Wesley, 1989.

13) Goldman, S.L., Nagel, R.N., and Preiss, K., Agile Competitors and Virtual Organizations, Strategies for Enriching the Customer. New York, N.Y., Von Nostrand Reinhold, 1995.

14) Goonatilake, S., and Khebbal, S., Intelligent Hybrid Systems, Chichester, England, John Wiley, 1994.

15) Hahen, G. and Griffiths, C., "A quantitative model for Technological Risk Assessment in the process of IT Transfer". Proceedings of the 3rd European Conference on the Evaluation of Information Technology, Bath University, Bath, UK, 29th November 1996, pp.35 -42, 1996.

16) Holland, J.H., "Genetic Algorithms", Scientific American. July 1992, pp.44-50, 1992.

17) Jacobsen, H.A., "Generic architecture for hybrid intelligent systems", Proceedings of the 1998 IEEE International Conference on Fuzzy Systems, Part 1 (of 2), Anchorage, USA, May 4-9 1998, pp.709-714, 1998.

18) Kidd, P.T., Agile Manufacturing : Forging New Frontiers, Wokingham, England, Addison-Wesley, 1994.

19) Kornbluh, K., "Math and Science Software : Technology 1999 Analysis and Forecast", IEEE Spectrum, 36, 1, pp.88-91, 1999.

20) Kurzweil, R., The Age of Intelligent Machines, Cambridge, MA, MIT Press, 1992.

21) Liker, J.K., Fleischer, M., and Arnsdorf, D., "Fulfilling the promises of CAD", Sloan Management Review, Spring 1992, pp.74-86, 1992.

22) Mackerle, J., and Orsborn, K., "Expert systems for Finite Element Analysis and Design Optimisation - A Review", Engineering Computations, 5, pp90-102, 1988.

23) Meredith J.R., "The role of manufacturing technology competitiveness: Peerless laser processors", IEEE Transactions on Engineering Management, 35, 1, pp.3$10,1988$.

24) Reich, Y., "Layered models of research methodologies", Artificial Intelligence for Engineering Design, Analysis and Manufacturing, 8, 4, pp.263-274, 1994.

25) Rzevski, G. 1998. "Engineering Design for the next Millenium : The Challenge of Artificial Intelligence", The $86^{\text {th }}$ Thomas Hawksley Memorial Lecture, Institute of Mechanical Engineers (IMechE), December, 1998.

26) Sharif, A.M., "Neural and Evolutionary Computing in Finite Element Analysis", Journal of Computing and Information Technology, 7 (to appear), 1999.

27) Sharif, A., "The Management of Intelligence-Assisted Finite Element Analysis Technology", Proceedings of the Portland International Conference of Management of Engineering and Technology (PICMET '97), Portland, July 2731st 1997, pp. 2550-2555, 1997.

28) Sharif, A.M., and Barrett, A.N., "Utilising knowledge for optimum mesh design". IEE Colloquiam on Knowledge Discovery and Data Mining, IEE, London, 7-8 May 1998. Digest No. 98/310, London, Institute of Electrical Engineers (IEE), pp. 4/1-4/5, 1998.

29) Simon, H.A., The Sciences of the Artificial, Reading, MA, MIT Press, 1969.

30) Simon, H.A., "Artificial Intelligence : an empirical science", Artificial Intelligence, 77, pp.95-127, 1995. 
Sharif, A.M. (1999). "Harnessing agile concepts for the development of Intelligent Systems". New Generation Computing, 17 (4) : 369-380.

31) Steinberg, L., "Research Methodology for AI and Design", Artificial Intelligence for Engineering Design, Analysis and Manufacturing, 8, pp.283-287, 1994.

32) Strom, J.D., and Darden, L., "Is artificial intelligence a degenerating program?: A review of Hubert Dreyfus' what computers still can't do", Artificial Intelligence, 80, 1, pp.151-170, 1996.

33) Szabo, B. A., and Actis, R.L., "Finite Element Analysis in Professional practice", Computer Methods in Applied Mechanics and Engineering, 133, 3-4, pp.209$228,1996$.

34) Tsai, W.T., Heisler, K.G., Volovik, D., and Zualkernan, I.A., "Critical look at the relationship between AI and software engineering", IEEE Workshop on Language for Automatic Symbiotic and Intelligent Robotics, pp.2-18, 1988.

35) $\mathrm{Wu}, \mathrm{X}$., Ramakrishnan, S., and Schmidt, H., "Knowledge objects", Informatica (Ljubljana ed.), 19, 4, pp.557-571, 1995. 